\title{
Assessment of the Performance and Surface Alteration of Two Single-file Systems According to the Number of Uses
}

\author{
Márcia Virginia M. Porto-Pires ${ }^{1}$ \\ https://orcid.org/0000-0001-6302-0648 \\ Cleber Keiti Nabeshima ${ }^{1}$ \\ https://orcid.org/0000-0003-3340-0388 \\ Hector Caballero-Flores ${ }^{1}$ \\ https://orcid.org/0000-0001-5479-8263
}

\section{Manoel Eduardo de Lima Machado ${ }^{1 *}$ \\ https://orcid.org/0000-0001-7899-4576}

1University of São Paulo, School of Dentistry, Department of Restorative Dentistry, São Paulo, São Paulo, Brazil.

Received: 2018.10.10; Accepted: 2020.06.01.

*Correspondence: professormachado@hotmail.com; Tel.: +55-11-999932993

\section{HIGHLIGHTS}

- Both WaveOne and One Shape NG systems can safety be used more than once.

- WaveOne and One Shape NG files have different surface treatments.

- Single-file systems can result in different surface alterations after multiple uses.

- Single-file systems have different working times according to the number of uses.

\begin{abstract}
The aim of this study was to assess the performance and surface alteration of two single-file systems according to the number of uses. Ten WaveOne Primary files (25/.08) and ten One Shape NG files (25/.06) were used for instrumentation of mesial root canals of mandibular molars. Each instrument was cleaned and sterilized after the preparation of two root canals and then reused. The time spent for instrumentation of each root canal was recorded and analyzed by using t-test. Microphotographs of the surface of the instruments were taken with a scanning electron microscope at different magnifications (i.e. 18x, 160x, 500x and 1000x) and at a distance of $4 \mathrm{~mm}$ from the instrument's tip before being analyzed by four observers. Presence of disruption of cutting edge, crack, craters and unwinding was assessed and submitted to Fisher's exact test. Both systems showed manufacturing defects and cracks. The presence of disruption of cutting edges was major in WaveOne files from the sixth use, whereas One Shape NG files showed more unwinding. Only preparation time using WaveOne files was influenced by the number of uses. One can conclude that WaveOne files had more disruption of cutting edges and took longer time for root canal preparation from the sixth use onwards, whereas the One Shape NG files showed more unwinding at the tenth use.
\end{abstract}

Keywords: single-file; reuse; root canal instrumentation. 


\section{INTRODUCTION}

Nickel-titanium rotary instruments have enabled a more uniform preparation of root canals in a shorter working time and without loss of quality from the microbiological standpoint [1-5]. Among these instruments, systems have been proposed despite their differentiation in terms of design, alloy treatment and type of movement $[4,5]$. The WaveOne system consists of a single file made of nickel-titanium M-wire with a convex triangular cross-section and uses a reciprocating motion. The One Shape New Generation (NG) system also consists of a single file, but it is made of conventional nickel-titanium and uses continuous rotation. Its crosssection is varied in that it has a S-shaped format with two cutting angles in the portion closest to the shaft, a transition format with 2 to 3 cutting angles in the middle portion and a triangle format with asymmetric radii in the final $2 \mathrm{~mm}$ of the file [5].

Studies have demonstrated that reciprocating motion results in better resistance of the instruments than continuous rotary motion [6,7]. Furthermore, the nickel-titanium M-Wire is a heat-treated alloy with a microstructure containing martensite, which improves the fatigue resistance of the instruments $[8,9]$.

The search for more resistant instruments is a reflection of the concerns towards their fracture during endodontic treatment [10]. Sattapan and coauthors [11] reported that instrument fracture may occur due to torsion or bending. Torsional fractures exhibit previous signs of unwinding, but bending fatigue does not cause visible deformation [11] and therefore some instruments may fracture without any sign [12].

The manufacturer's recommendation for automated systems is that the file should be disposed after its first use in one molar, which minimizes the incidence of load on the instrument and consequently reduces the risk of fracture. However, factors related to endodontic treatment cost and different social realities should be taken into consideration. According to some authors, further research should be conducted in order to determine the instrument safety regarding the number of uses [13,14]. Therefore, the study of microscopic changes in the instrument following root canal preparation is justified not only because they are defects leading to fracture $[10,14,15]$, but also because its disposal is also related to changes or poor cutting [13]. Therefore, the aim of this study was to assess the performance and surface alteration of two single-file systems - WaveOne and One Shape NG - according to the number of uses.

\section{MATERIAL AND METHODS}

After approval by the local research ethics committee (CEP/FOUSP 736.043), 10 WaveOne Primary files (25/.08, Dentsply Maillefer, Ballaigues, VD, Switzerland) and 10 One Shape NG files \#25/.06 (Micromega, Besançon, FR-I, France) were removed from the packaging and attached to stubs for observation with a scanning electron microscope operating at $25 \mathrm{kv}$ (JSM 5900LV, JEOL, Tokyo, Japan). Microphotographs were taken at 160x, 500x and 1000x magnifications at a distance of $4 \mathrm{~mm}$ from the instrument's tip for presence and absence of disruption of cutting edge, crack or craters.

Next, 200 mesial root canals of mandibular molars were selected, with all roots presenting complete rhizogenesis and Vertucci type IV configuration (i.e. two canals running separately from orifice to apex), round and narrow root canals with initial apical diameter no greater than a size \#15 K-file, curvature angles between $15^{\circ}$ to $30^{\circ}$ and radius of $5 \mathrm{~mm}$ to $9 \mathrm{~mm}$ [16], and absence of calcifications, resorption, root fractures and previous endodontic treatment. The root canals were accessed and randomly divided into two groups according to the instrument used, namely, Group WS using WaveOne Primary files and Group OS using One Shape NG files \#25/.06.

The root canals were previously irrigated with $2 \mathrm{ml}$ of $2.5 \%$ sodium hypochlorite (Fórmula e Ação, São Paulo, SP, Brazil) before introducing a \#15 K-file (Dentsply Maillefer, Ballaigues, VD, Switzerland) into them until reaching the foramen in order to determine the working length at $1 \mathrm{~mm}$ short from the foraminal opening. Next, the tooth was attached with C-silicone putty (Perfil, Vigodent, Rio de Janeiro, RJ, Brazil).

WaveOne Primary instruments were used with an endodontic motor (VDW Silver, VDW, Munich, DEBY, Germany) set at mode WaveOneALL. The file was inserted into the root canal with three pecking motions in the apical direction, followed by root canal negotiation using a \#15K-file. This sequence was repeated until the working length was determined.

One Shape NG instruments were used with an endodontic motor (VDW Silver) operating at a speed of $400 \mathrm{rpm}$ in continuous rotation and torque of $2.5 \mathrm{Ncm}$. The file was inserted into the root canal by using an in-and-out motion with slight apical pressure at an amplitude of approximately $3 \mathrm{~mm}$ every three times before being removed, followed by a root canal negotiation by using a \#15K-file. These movements were repeated until the working length was determined. 
Irrigation was performed at every removal of the file, totalizing $10 \mathrm{ml}$ of $2.5 \%$ sodium hypochlorite during the root canal preparation. The time spent in each root canal preparation was recorded in seconds with a digital chronometer, except the irrigation time.

The files were cleaned with sponge and detergent after the preparation of two root canals of a mandibular molar, followed by ultrasonic bath in $70 \%$ ethanol for 10 minutes and sterilized in autoclave before observation with scanning electron microscope, as previously described.

Each instrument was used in up to 10 root canals, with each group having 10 instruments assessed. All root canal preparations were performed by a single experienced endodontist.

The observation with scanning electron microscope was performed after 2, 6, 8 and 10 uses, as previously described. Unwinding was also observed at 18x magnification after the tenth use.

Four previously calibrated observers, whose inter-rater reliability was validated by Kappa test (Cohen's coefficient between 0.81 and 1.0, i.e., perfect), assessed the microphotographs and the resulting data were submitted to Fisher's exact test for comparison between the systems and number of uses. The experimental times were submitted to Lilliefors test for data normality before using independent t-test for comparison between the systems in each use and paired t-test for comparison of the number of uses. All statistical analyses were performed at significance level of $5 \%$.

\section{RESULTS}

\section{Scanning Electron Microcopy}

The characteristics of the instruments were observed in both groups. WaveOne files showed cutting edges resembling curls of wave and a surface with machining marks perpendicular to the long axis of the instrument (Figure 1 A-B). Differently, One Shape NG files had a smooth surface with slight machining traces and standard cutting edge angles (Figure $1 \mathrm{C}$ ). 

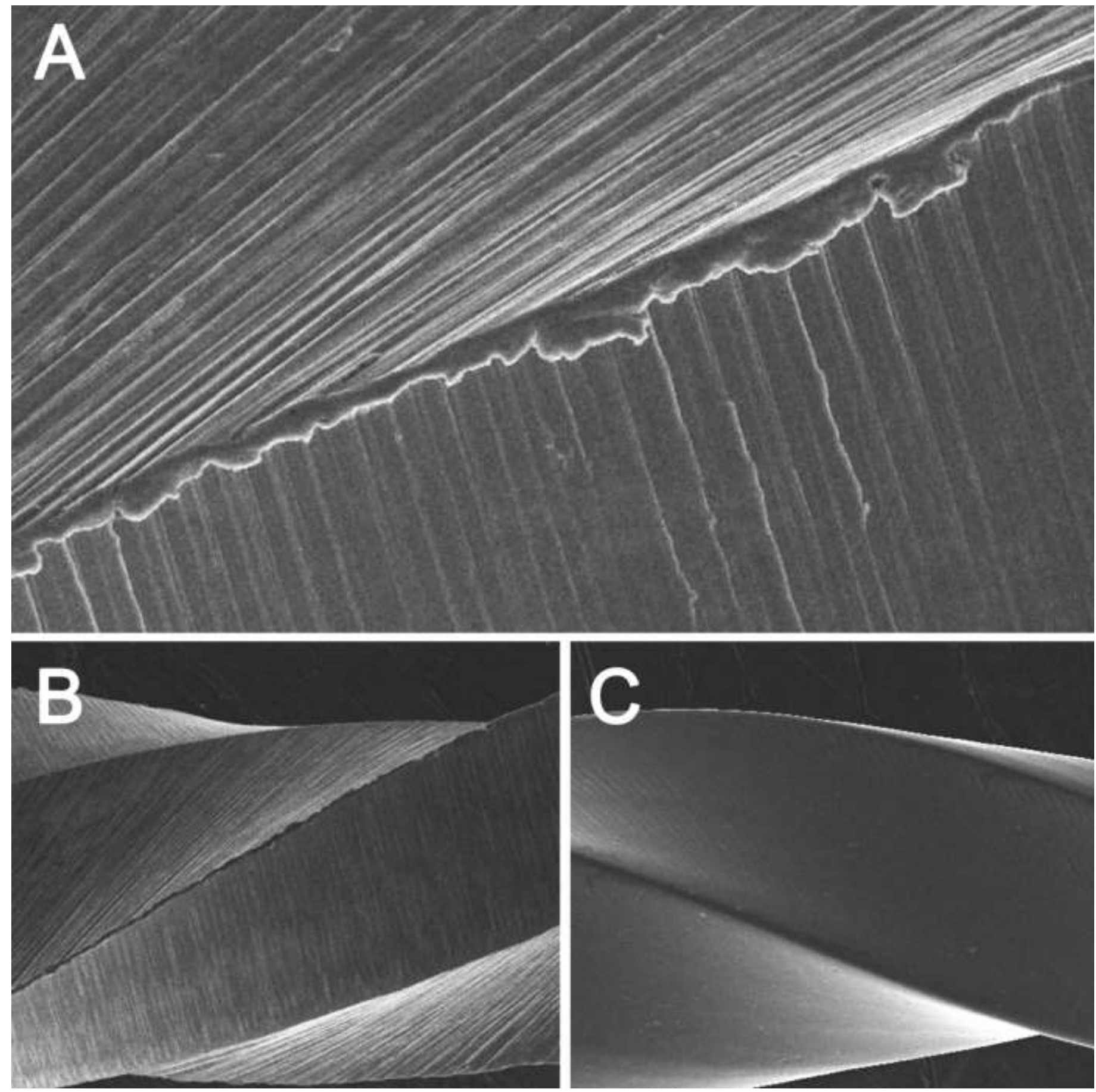

Figure 1. Microphotograph of the unused instruments. (A) Cutting edges resembling a "wave curl" in files of the WaveOne system (original magnification, 500x); (B) Machining marks on the surface of files of the WaveOne system (original magnification, 160x); and (C) Smooth surface of files of the One Shape NG system (original magnification, 160x).

Disruption of cutting edges was present in unused WaveOne files (Figure 2 A), whereas One Shape NG files had craters (Figure $2 \mathrm{~B}$ ). However, the disruption of cutting edges was significantly greater in WaveOne instruments from the sixth use onwards $(P<0.05)$. Cracks emerged in WaveOne and One Shape NG files from the second and tenth uses, respectively (Figure $2 \mathrm{C}-\mathrm{D}$ ), but this defect was similar between the systems $(P>0.05)$ and did not significantly increase according to the number of uses $(P>0.05)$. Unwinding after the tenth use was more present in the One Shape NG than in WaveOne files $(P<0.05)$. The number of instruments showing surface alteration according to the number of uses is described in Table 1. 

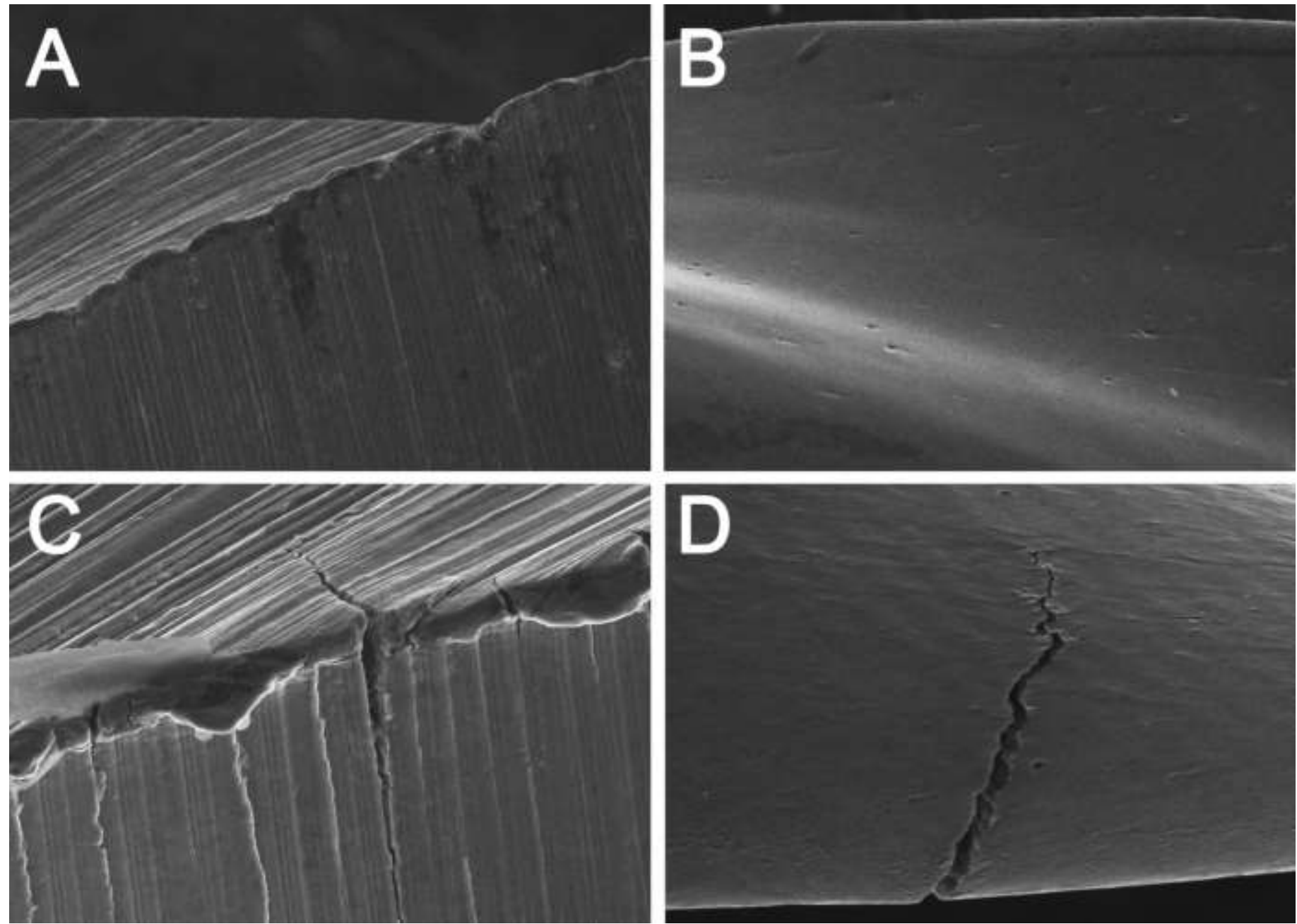

Figure 2. Microphotograph of the defects on the surface instruments. (A) Disruption of cutting edges in files of the WaveOne system (original magnification, 500x); (B) Craters on the surface of files of the One Shape NG system (original magnification, 500x); (C) Cracked cutting edges in files of the WaveOne and (D) One Shape NG systems (original magnification, 1000x).

Table 1. Surface alteration of the WaveOne and One Shape NG according to the number of uses

\begin{tabular}{lllllllll}
\hline \multicolumn{3}{l}{ WaveOne } & \multicolumn{7}{c}{ One Shape NG } \\
\hline Uses & DCE & Craters & Crack & U & DCE & Craters & Crack & U \\
\hline 0 & $3(30 \%)$ & 0 & 0 & - & 0 & $4(40 \%)$ & 0 & - \\
2 & $3(30 \%)$ & 0 & $2(20 \%)$ & - & 0 & $4(40 \%)$ & 0 & - \\
6 & $5(50 \%)$ & 0 & $4(40 \%)$ & - & 0 & $4(40 \%)$ & 0 & - \\
8 & $6(60 \%)$ & 0 & $4(40 \%)$ & - & 0 & $4(40 \%)$ & 0 & - \\
10 & $7(70 \%)$ & 0 & $4(40 \%)$ & $2(20 \%)$ & 0 & $4(40 \%)$ & $3(30 \%)$ & $9(90 \%)$ \\
\hline
\end{tabular}

DCE $=$ Disruption of cutting edges. $\mathrm{U}=$ Unwinding

Only One Shape NG files fractured at $4 \mathrm{~mm}$ from the tip during essays.

\section{Working Time}

The comparison between number of uses and the first use demonstrated that the working time for root canal preparation increased from the sixth use for WaveOne files $(P<0.05)$. The working time for root canal preparation was similar in all uses for One Shape NG files $(P>0.05)$. The comparison between the systems indicated that root canal preparation time was shorter with One Shape NG compared to WaveOne instruments, but only from the fifth use $(P<0.05)$. Figure 3 shows the time variation according to the number of uses. 


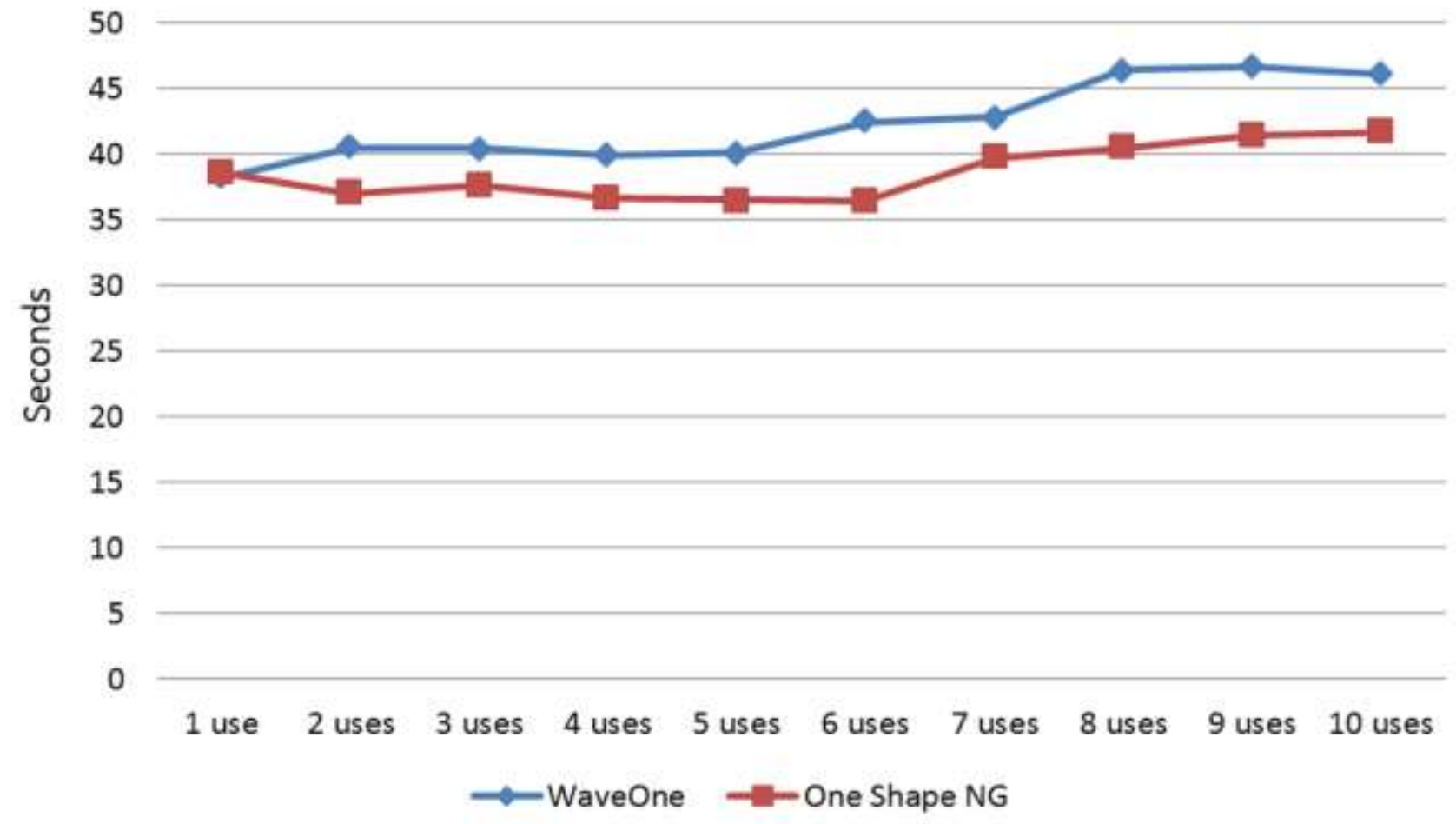

Figure 3. Mean values of working time for WaveOne and One Shape NG systems according to the number of uses.

\section{DISCUSSION}

Strength and number of uses of endodontic instruments have been investigated to determine a safer instrumentation as they may suffer fractures due to the stress caused during root canal preparation and variations in root canal curvature [17,18]. This study aimed at assessing the surface alteration and performance during the reuse of two single-file systems, with both exhibiting some different behaviors depending on the number of uses.

The different motions of these systems are due to the fact that some clinicians do not have reciprocating endodontic motor. However, studies demonstrated that design, taper, tip and alloy treatment can influence both torsional strength and cyclic fatigue of the instruments $[19,20]$.

The working time was used to assess the performance of the instruments in terms of cutting ability according to the number of uses [12]. Moreover, scanning electron microscopy was chosen for analysis of the instrument surfaces following previous essays [10,13,17,21-23]. Although other authors have used stereomicroscopy [11,12], the use of scanning electron microscopy is justified because some fracture-related changes are seen at high magnifications only, which is not possible with an operation microscope [14]. The 4-mm region from the tip of the instrument was chosen for evaluation because it is where the fracture usually occurs [11,12,24], and mandibular molars were used because the incidence of instrument fracture is high in these teeth $[11,17,24,25]$.

Analysis of the instrument surface has shown that each system had characteristic defects. WaveOne files had presence of disruption of cutting edges, whereas One Shape NG files exhibited craters. However, these defects were seen in unused instruments, demonstrating that such defects were the result of the manufacturing process. These findings are corroborated by other authors, who also observed these characteristics in unused instruments [15,21-24,26]. The difference in defects between unused instruments can be explained by their surface treatment, since One Shape NG files exhibited smooth surface or slight machining marks and the WaveOne files only features of the electropolishing procedures [27]. In this context, Kim and coauthors [15] reported that the presence of craters is a common defect found in some electropolished instruments, which is in accordance with the present study. Although the disruption of cutting edges was present in unused WaveOne files, this defect increased from the sixth use - a finding also corroborated by Pirani and coauthors [21], who also found such a disruption in this system according to the 
number of use. For some authors, the irregular edges found in unused WaveOne files were thought to be a defect [22,23]. However, Pirani and coauthors [21] and our study showed that these cutting edges actually resemble a wave-curl present in these instruments and therefore they should not be considered a defect.

Cracks were observed in both systems when the files were reused, another finding also reported by authors who assessed the multiple use of automated files $[10,14,15]$. This defect was observed in two WaveOne files after the second use and in more two files after the sixth use. These results are similar to those reported by Park and coauthors. [13] and Pirani and coauthors [21], who observed the emergence of cracks in WaveOne files after the fifth and third uses, respectively. This defect was seen in three One Shape NG instruments only after the tenth use. Although some WaveOne files had exhibited cracks earlier than the One Shape NG instruments, this figure was low and there was no statistically significant difference between systems and number of uses.

Despite the emergence of cracks, the One Shape NG system had only one file fractured, which occurred after the tenth use with no statistically significant difference between the groups. This is corroborated by Caballero and coauthors [28], who also found no statistically significant difference in the incidence of fractures in files reused with continuous rotation or reciprocating motion. On the other hand, in vitro studies have demonstrated that both reciprocating motion and heat treatment of $\mathrm{Ni}$-Ti alloy provide instruments with higher cyclic fatigue strength $[6,7,9]$. These results should be better interpreted in terms of clinical use, since the present study showed no difference between both systems regarding number of fractures, type of motion and alloy treatment. As for the number of root canals, other authors also found no fracture in WaveOne and One Shape systems after instrumentation of 3 to 10 root canals $[3,13,21,28]$, except one study reporting fracture of one instrument during a third clinical use in a posterior tooth[12].

Unwinding is a feature that may be visible before fracture [11]. This study has demonstrated it in the One Shape NG system, which might be explained by the continuous rotary motion. Similar results were found by Caballero and coauthors [28], who observed unwinding in a single-file system operating at continuous rotary motion, a finding also confirmed by other authors who did not detect any deformation in reciprocating instruments $[12,17]$. In addition, the absence of heat treatment of nickel titanium alloy may have contributed to this difference, since M-Wire alloy has greater flexibility and torsional strength than conventional nickeltitanium alloy $[9,19]$. However, although unwinding was more present in the One Shape NG than in WaveOne system, no difference was found between them regarding fracture.

It is important to mention that instrument fracture during clinical procedure is multifactorial as this event is related to bending and torsion loads to which the files are submitted during root canal preparation, including tooth position, root curvature and root canal diameter [17]. The present study standardized the curvature angle of the root canal to allow the comparison between the systems without considering the variable root canal anatomy. Nevertheless, this topic should be considered in function of the number of reuses of the instruments in the clinical practice. Caballero-Flores and coauthors [25] observed that the WaveOne files can be clinically reused up to six root canals, with low incidence of fracture $(0.92 \%)$. This finding is in accordance with our results because the disruption of cutting edges was the only statistically significant defect, increasing from the sixth use onwards.

The reduction in the risk of fracture is one of the reasons why manufacturers recommend the disposal of the instrument after its first use. The results demonstrated that the emergence of surface defects is not significant before the sixth root canal preparation. By considering that the single use refers to a molar (two root canals in a mandibular molar), the reuse in up to six root canals seems to be acceptable as it was demonstrated that instruments can be reused in more than one molar. However, this study has evaluated the defects on the surface of the instruments and therefore essays evaluating their internal structure should be encouraged to complement our findings.

The present study has found mean times of 39.7 and 37.4 seconds for root canal instrumentation by using, respectively, WaveOne and One Shape NG systems up to four uses. However, Burklein and coauthors [2] and Burklein and coauthors [29] reported mean times of 82.3 and 80.7 seconds, respectively, for WaveOne and One Shape systems. These results can be explained by the fact that these authors instrumented severely curved root canals, which was confirmed when Burklein and coauthors [30] reported a mean time of 43.2 seconds by using One Shape files in straight root canals. As for the influence of number of uses, WaveOne instruments had a reduced performance after the sixth use, whereas One Shape NG files showed no difference up to the tenth root canal being instrumented. The comparison between systems demonstrated that they behaved differently after the sixth use, with their performance being possibly influenced by the increased disruption of cutting edges. Working time can bring important information on the instrument's behavior and performance after successive uses [13]. Park and coauthors [13] also observed that the number of uses increased the working time for root canal preparations in the WaveOne system. 
However, it is important to mention that these statistical differences are based on numerical values measured in seconds, which may be irrelevant in the clinical practice.

\section{CONCLUSION}

In view of the results, one can conclude that WaveOne files presented more disruption of cutting edges and required longer time for root canal preparation from the sixth use onwards, whereas the One Shape NG instruments showed more unwinding in the tenth use.

Funding: This research was funded by Coordenação de Aperfeiçoamento de Pessoal de Nível Superior (CAPES).

Acknowledgments: The authors thank LNLS - Brazilian Synchrotron Light Laboratory, CNPEM/MCTI for support.

Conflicts of Interest: The authors declare no conflict of interest. The funders had no role in the design of the study; in the collection, analyses, or interpretation of data; in the writing of the manuscript, or in the decision to publish the results.

\section{REFERENCES}

1. Taşdemir $\mathrm{T}$, Aydemir $\mathrm{H}$, Inan $\mathrm{U}$, Ünal $\mathrm{O}$. Canal preparation with Hero 642 rotary Ni-Ti instruments compared with stainless steel hand K-file assessed using computed tomography. Int Endod J. 2005;38(6):402-8.

2. Bürklein S, Hinschitza K, Dammaschke T, Schäfer E. Shaping ability and cleaning effectiveness of two single-file systems in severely curved root canals of extracted teeth: Reciproc and WaveOne versus Mtwo and ProTaper. Int Endod J. 2012;45(5):449-61.

3. Machado ME, Nabeshima CK, Leonardo MF, Reis FA, Britto ML, Cai S. Influence of reciprocating single-file and rotary instrumentation on bacterial reduction on infected root canals. Int Endod J. 2013;46(11):1083-7.

4. Nabeshima CK, Caballero-Flores H, Cai S, Aranguren J, Borges Britto ML, Machado ME. Bacterial removal promoted by 2 single-file systems: Wave One and One Shape. J Endod. 2014;40(12):1995-8.

5. Guillén RE, Nabeshima CK, Caballero-Flores H, Cayón MR, Mercadé M, Cai S, et al. Evaluation of the WaveOne Gold and One Shape New Generation in reducing Enterococcus faecalis from root canal. Braz Dent J. 2018;29(3):249-53.

6. De-Deus G, Moreira EJ, Lopes HP, Elias CN. Extended cyclic fatigue life of F2 ProTaper instruments used in reciprocating movement. Int Endod J. 2010;43(12):1063-8.

7. Varela-Patiño P, Ibañez-Párraga A, Rivas-Mundiña B, Cantatore G, Otero XL, Martin-Biedma B. Alternating versus continuous rotation: A comparative study of the effect on instrument life. J Endod. 2010;36(1):157-9.

8. Alapati SB, Brantley WA, lijima M, Clark WA, Kovarik L, Buie C, Liu J, Ben Johnson W. Metallurgical characterization of a new nickel-titanium wire for rotary endodontic instruments. J Endod. 2009;35(11):1589-93.

9. Pereira ESJ, Peixoto IFC, Viana ACD, Oliveira II, Gonzalez BM, Buono VTL, et al. Physical and mechanical properties of a thermomechanichally treated NiTi wire used in the manufacture of rotary endodontic instruments. Int Endod J. 2012;45(5):469-74.

10. Alapati SB, Brantley WA, Svec TA, Powers JM, Nusstein JM, Daehn GS. SEM observations of nickel-titanium rotary endodontic instruments that fractured during clinical use. J Endod. 2005;31(1):40-3.

11. Sattapan B, Nervo GJ, Palamara JE, Messer HH. Defects in rotary nickel-titanium files after clinical use. J Endod. 2000;26(3):161-5.

12. Bueno CSP, Oliveira DP, Pelegrine RA, Fontana CE, Rocha DGP, Bueno CES. Fracture incidence of WaveOne and Reciproc files during root canal preparation of up to 3 posterior teeth: A prospective clinical study. J Endod. 2017;43(5):705-8.

13. Park SK, Kim YJ, Shon WJ, You SY, Moon YM, Kim HC, et al. Clinical efficiency and reusability of the reciprocating nickel-titanium instruments according to the root canal anatomy. Scanning. 2014;36(2):246-51.

14. Vieira EP, França EC, Martins RC, Buone VTL, Bahia MGA. Influence of multiple clinical use on fatigue resistance of ProTaper rotary nickel-titanium instruments. Int Endod J. 2008;41(2):163-72.

15. Kim HC, Yum J, Hur B, Cheung GS. Cyclic fatigue and fracture characteristics of ground and twisted nickel-titanium rotary files. J Endod. 2010;36(1):147-52.

16. Pruett JP, Clement DJ, Carnes DL Jr. Cyclic fatigue testing of nickel-titaniun endodontic instruments. J Endod. 1997;23(2):77-85.

17. Wu J, Lei G, Yan M, Yu Y, Yu J, Zhang G. Instrument separation analysis of multi-used ProTaper Universal rotary system during root canal therapy. J Endod. 2011;37(6):758-63.

18. Castelló-Escrivá R, Alegre-Domingo T, Faus-Matoses V, Román-Richon S, Faus-Llácer VJ. In vitro comparison of cyclic fatigue resistance of ProTaper, WaveOne, and Twisted Files. J Endod. 2012;38(11):1521-4. 
19. Alqedairi A, Alfawaz H, Abualjadayel B, Alanazi M, Alkhalifah A, Jamleh A. Torsional resistance of three ProTaper rotary systems. BMC Oral Health. 2019;19(1):124.

20. Pérez-Higueras JJ, Arias A, de la Macorra JC, Peters OA. Differences in cyclic fatigue resistance between ProTaper Next and ProTaper Universal instruments at different levels. J Endod. 2014;40(9):1477-81.

21. Pirani C, Paolucci A, Ruggeri O, Bossü M, Polimeni A, Gatto MRA, et al. Wear and metallographic analysis of WaveOne and Reciproc NiTi instruments before and after trhee uses in root canals. Scanning. 2014; 36(5):51725.

22. Hanan AR, Meireles DA, SponchiadoJúnior EC, Hanan S, Kuga MC, BonettiFilho I. Surface characteristics of reciprocating instruments before and after use - A SEM analysis. Braz Dent J. 2015;26(2):121-7.

23. Bastos MMB, Hanan ARA, Bastos AMB, Marques AAF, Garcia LDFR, Sponchiado Júnior EC. ASTO. Topographic and chemical analysis of reciprocating and rotary instruments surface after continuous use. Braz Dent $\mathrm{J}$. 2017;28(4):461-6.

24. Shen Y, Cheung GS, Bian Z, Peng B. Comparison of defects in ProFile and ProTaper systems after clinical use. J Endod. 2006;32(1):61-5.

25. Caballero-Flores H, Nabeshima CK, Binotto E, Machado MEL. Fracture incidence of instruments from a single-file reciprocating system by students in an endodontic graduate programme: a cross-sectional retrospective study. Int Endod J. 2019;52(1):13-8.

26. Tripi TR, Bonaccorso A, Tripi V, Condorelli GG, Rapisarda E. Defects in GT rotary instruments after use: an SEM study. J Endod. 2001;27(12):782-5.

27. Chianello G, Specian VL, Hardt LC, Raldi DP, Lage-Marques JL, Habitante SM. Surface finishing of unused rotary endodontic instruments: a SEM study. Braz Dent J. 2008;19(2):109-13.

28. Caballero H, Rivera F, Salas H. Scanning electron microscopy of superficial defects in Twisted files and Reciproc nickel titanium files after use in extracted molars. Int Endod J. 2015;48(3):229-35.

29. Bürklein S, Benten S, Schäfer E. Shaping ability of different single-file systems in severely curved root canals of extracted teeth. Int Endod J. 2013;46(6):590-7.

30. Bürklein S, Benten S, Schäfer E. Quantitative evaluation of apically extruded debris with different single-file systems: Reciproc, F360 and OneShape versus Mtwo. Int Endod J. 2014;47(5):405-9.

2020 by the authors. Submitted for possible open access publication under the terms and conditions of the Creative Commons Attribution (CC BY NC) license (https://creativecommons.org/licenses/by-nc/4.0/). 